\title{
Neuro-oncology tracers: an already limited supply impacted by the pandemic?
}

Yazeed Aldalilah, Francesco Fraioli ${ }^{\mathrm{a}}$ and Jamshed Bomanji

aUniversity College London Institute of Nuclear Medicine, UK

Correspondence to Francesco Fraioli, MD, University College London Institute of Nuclear Medicine, UK

On the smooth service road of the UK oncology highway, the PET/computed tomography (PET/CT) motor hit a bumpy patch during the coronavirus disease (COVID19) pandemic. Apart from service volumes being downsized with the lockdowns and coming back to the new normal as lockdowns are eased, the community also experienced radiotracer supply issues. The commercial manufacturers suffered collateral damage with dwindling numbers and were forced to rationalize and streamline the production line to comply with the change in work practice, protect staff and maintain fiscal stability. This has led to some tracers being shelved. The Fluorine-18 $\left({ }^{18} \mathrm{~F}\right)$-based amino acid PET tracers are one such casualty. Before the COVID-19 pandemic, the production of ${ }^{18} \mathrm{~F}$-choline, ${ }^{18} \mathrm{~F}$-fluoroethyltyrosine (FET) and ${ }^{18} \mathrm{~F}$-fluorothymidine (FLT) was suffering. The arrival of the COVID-19 pandemic put a final nail in the coffin, and commercial manufacturers cut production of rarely used tracers which are now limited to academic cyclotron centres who may or may not produce that radiopharmaceutical or a similar tracer. In urology, the absence of ${ }^{18} \mathrm{~F}$-choline has led to the fortunate use of prostate-specific membrane antigen (PSMA) as a replacement; however, in neuro-oncology, there are few alternatives, currently, ${ }^{18} \mathrm{~F}$-fluorophenylalanine (FDOPA) being the most common. The scope of this editorial is to try and understand the main factors responsible for the underuse of this modality and discuss some mitigation factors.

First of all, one can argue that the availability of these tracers is linked to demand, which is ultimately related to the outcome and prognosis of the disease. The fact remains that the prognosis of gliomas, particularly highgrade gliomas, is poor [1], and if there are no effective treatment options, then the need for higher diagnostic accuracy is of less significance. Second, when it comes to baseline assessment, the issue of logistics is apparent as these patients often present with acute symptoms and require urgent management which leaves little room for arrangement of a PET scan while MRI is much quicker and easier to obtain. The use of ${ }^{11} \mathrm{C}$-methyl methionine (MET PET, in particular, requires an onsite cyclotron due to the short half-life of the radio-isotope Carbon $11\left({ }^{11} \mathrm{C}\right)$ which is only 20 mins. Third, there is no reimbursement available under the NHS tariff system for the use of ${ }^{18} \mathrm{~F}$-DOPA
E-mail: francesco.fraioli@nhs.net

Received 4 August 2020 Accepted 21 August 2020

PET. This is further complicated by the fact that these patients will often require more than one PET scan, increasing cost and time. Additionally, highly specialized PET tracers might be affected in the case of a no-deal BREXIT. Generally speaking, this should not be an issue as most PET tracers are produced by cyclotrons throughout the UK or by long-lived generators (https://www.rcr. ac.uk/sites/default/files/no_deal_brexit_planning_guidance_for_nuclear_medicine_teams_march_2019.pdf). Finally, there are still no clear guidelines for patient selection neither reproducible methods of analysis and most of the published literature rely on offline or in house developed software which are difficult to reproduce on a large scale across several institutions.

Although the usage of PET imaging is currently low, there has been a growing interest in its use for the management of brain tumours. Compared to MRI, PET imaging offers the advantage of imaging specific metabolic pathways which can improve the sensitivity and specificity for detecting gliomas [2]. The growing interest of using PET imaging is evident by the recently published joint guidelines by the European Association of Nuclear Medicine (EANM), the Society of Nuclear Medicine and Molecular Imaging (SNMMI), the European Association of Neuro-Oncology (EANO) and the Response assessment in neuro-oncology (RANO) working group for the use of PET imaging in the management of gliomas [3]. The currently available radiotracers for imaging gliomas in clinical practice include tracers that utilize the system-L amino acid transporters, and they include MET, FET and FDOPA in addition to ${ }^{18} \mathrm{~F}$-Fluorodeoxyglucose (FDG) which reflects glucose metabolism. Despite the rapid progress of PET in neuro-oncology imaging during the last decade, MRI remains the standard imaging modality of choice. MRI relies heavily on contrast enhancement for the evaluation of brain tumours [4]; however, relying solely on contrast enhancement is unreliable as the blood-brain barrier (BBB) can be affected by multiple factors including surgery, radiation, steroids and antiangiogenic therapies resulting in reduced specificity [5-7]. PET imaging can be used at the time of primary diagnosis (e.g., differentiation of high-grade from lowgrade glioma or non-neoplastic causes), for therapy monitoring, and to assess for disease recurrence [8]. The high 
physiological background activity limits the use of FDG in neuro-oncology imaging, and as such, its use is limited to specific indications such as the differentiation of tumour recurrence from radiation necrosis or the management of central nervous system lymphoma [9-11]. Amino acid PET has been shown to be superior to MRI in many clinical applications [8]. For example, at baseline assessment, MET and FET PET demonstrated higher diagnostic accuracy than MRI in the differentiation of gliomas from non-neoplastic causes. Furthermore, FET PET, in particular with dynamic acquisition, showed higher diagnostic accuracy in grading gliomas and in detecting anaplastic foci. Moreover, FET, MET and FDOPA PET consistently showed higher tumour volume as compared to MRI at baseline assessment. Similarly, amino acid PET is superior to MRI for the differentiation of treatment-related changes from tumour relapse [8]. Other notable tracers used in neuro-oncology include FLT and Choline. FLT is a thymidine analogue used to image tumour proliferation; however, thymidine analogues are not transported across an intact BBB which limits its use, particularly in low-grade gliomas [12]. Choline is incorporated into phospholipid synthesis, a major cell membrane component reflecting tumour cells rapid proliferation. In a systematic review by Dardel $e t$ al. [13], they reported a high diagnostic accuracy of choline PET in many clinical applications. One particular advantage of choline PET is its high tumour-to-background signal; however, there is not enough evidence to recommend choline over other wellestablished PET tracers.

The role of nuclear medicine is more evident in the posttreatment period as the detection of recurrent disease allows for the initiation of treatment earlier. Despite the current low utilization of PET imaging in neuro-oncology, the future is promising. The advent of theranostic PET in the field of neuro-oncology is gaining momentum [14]. PET imaging can be used to identify specific biological targets to deliver radionuclide therapy subsequently. Examples include PSMA and somatostatin receptors analogue imaging utilizing the DOTA tracers. Furthermore; there is a slew of promising new tracers that identify investigational therapeutic targets such as vascular endothelial growth factor, epidermal growth factor receptor, human epidermal growth factor receptor 2, programmed cell death receptor-1, CD8+ T-cells and isocitrate dehydrogenase mutations among others [15]. This will allow patient selection for potential therapies, particularly immunotherapy agents such as checkpoint inhibitors, Bevacizumab and chimeric antigen receptor T-cell therapy. As therapies targeting these specific pathways are developed and validated, the demand for PET imaging in neuro-oncology will increase accordingly, allowing for precision oncology practice. Another promising field is proton beam therapy (PBT), which delivers maximized radiation dose to the target tissue and minimizes the dose to nontarget tissue as compared to photon beam radiation [16]. The use of PET imaging to delineate the tumours volume and extent in this setting will become critical. PET imaging can also be used for quality assurance of PBT as it can be acquired during or soon after therapy to assess dose delivery [17].

It is difficult to predict the future of molecular imaging in neuro-oncology, but a key role will be played by the development and validation of new therapies and tracers, which will drive clinical demand. Improvements and adoption of new technologies such as multiparametric imaging (e.g., PET/MRI) may add further essential information in neuro-oncology [18]. Although some form of collaboration exists between RANO, EANO, EANM and SNMMI [12], there is room for improvement. Most management guidelines produced by organisations such as the EANO, European Society of Medical Oncology and the National Institute for Health Care and Excellence only briefly mention PET imaging. Such organizations would benefit from input by nuclear medicine societies when updating their guidelines [19,20]. The nuclear medicine fraternity, relevant royal colleges and our regulators and paymasters (NHS-E and MHRA) must remain engaged and help facilitate and adopt alternative radiopharmaceuticals and new technologies for patient benefit.

\section{Acknowledgement Conflicts of interest}

There are no conflicts of interest.

\section{References}

1 Ostrom QT, Cioffi G, Gittleman H, Patil N, Waite K, Kruchko C, et al. CBTRUS statistical report: primary brain and other central nervous system tumors diagnosed in the United States in 2012-2016. Neuro Oncol 2019; 21 (Suppl 5):v1-v100.

2 la Fougère C, Suchorska B, Bartenstein P, Kreth FW, Tonn JC. Molecular imaging of gliomas with PET: opportunities and limitations. Neuro Oncol $2011 ; 13: 806-819$.

3 Law I, Albert NL, Arbizu J, Boellaard R, Drzezga A, Galldiks N, et al. Joint EANM/EANO/RANO practice guidelines/SNMMI procedure standards for imaging of gliomas using PET with radiolabelled amino acids and [18F] FDG: version 1.0. Eur J Nucl Med Mol Imaging 2019; 46:540-557.

4 Macdonald DR, Cascino TL, Schold SC Jr, Cairncross JG. Response criteria for phase II studies of supratentorial malignant glioma. J Clin Oncol 1990; 8:1277-1280.

5 Dhermain FG, Hau P, Lanfermann $\mathrm{H}$, Jacobs $\mathrm{AH}$, van den Bent MJ. Advanced MRI and PET imaging for assessment of treatment response in patients with gliomas. Lancet Neuro/ 2010; 9:906-920.

6 Ahluwalia MS, Wen PY. Antiangiogenic therapy for patients with glioblastoma: current challenges in imaging and future directions. Expert Rev Anticancer Ther 2011; 11:653-656.

7 Kumar AJ, Leeds NE, Fuller GN, Van Tassel P, Maor MH, Sawaya RE, Levin VA. Malignant gliomas: MR imaging spectrum of radiation therapy- and chemotherapy-induced necrosis of the brain after treatment. Radiology 2000; 217:377-384.

8 Albert NL, Weller M, Suchorska B, Galldiks N, Soffietti R, Kim MM, et al. Response Assessment in Neuro-Oncology working group and European Association for Neuro-Oncology recommendations for the clinical use of PET imaging in gliomas. Neuro Oncol 2016; 18:1199-1208.

9 Omuro AM, Leite CC, Mokhtari K, Delattre JY. Pitfalls in the diagnosis of brain tumours. Lancet Neurol 2006; 5:937-948.

10 Yamashita K, Yoshiura T, Hiwatashi A, Togao O, Yoshimoto K, Suzuki SO, et al. Differentiating primary CNS lymphoma from glioblastoma multiforme: assessment using arterial spin labeling, diffusion-weighted imaging, and ${ }^{18} \mathrm{~F}$-fluorodeoxyglucose positron emission tomography. Neuroradiology 2013; 55:135-143. 
11 Kosaka N, Tsuchida T, Uematsu H, Kimura H, Okazawa H, Itoh H. ${ }^{18} \mathrm{~F}-\mathrm{FDG}$ PET of common enhancing malignant brain tumors. AJR Am J Roentgenol 2008; 190:W365-W369.

12 Saga T, Kawashima H, Araki N, Takahashi JA, Nakashima Y, Higashi T, et al. Evaluation of primary brain tumors with FLT-PET: usefulness and limitations. Clin Nucl Med 2006; 31:774-780.

13 Testart Dardel N, Gómez-Río M, Triviño-lbáñez E, Llamas-Elvira JM. Clinical applications of PET using C-11/F-18-choline in brain tumours: a systematic review. Clin Transl Imaging 2017; 5:101-119.

14 Pruis IJ, van Dongen G, Veldhuijzen van Zanten SEM. The added value of diagnostic and theranostic PET imaging for the treatment of CNS tumors. Int J Mol Sci 2020; 21:1029.

15 Werner JM, Lohmann P, Fink GR, Langen KJ, Galldiks N. Current landscape and emerging fields of PET imaging in patients with brain tumors. Molecules 2020; 25:1471.
16 Wilson RR. Radiological use of fast protons. Radiology 1946; 47:487-491.

17 Hishikawa Y, Kagawa K, Murakami M, Sakai H, Akagi T, Abe M. Usefulness of positron-emission tomographic images after proton therapy. Int J Radiat Oncol Biol Phys 2002; 53:1388-1391.

18 Fraioli F, Shankar A, Hargrave D, Hyare H, Gaze MN, Groves AM, et al. 18F-fluoroethylcholine (18F-Cho) PET/MRI functional parameters in pediatric astrocytic brain tumors. Clin Nucl Med 2015; 40:e40-e45.

19 Stupp R, Brada M, van den Bent MJ, Tonn JC, Pentheroudakis G; ESMO Guidelines Working Group. High-grade glioma: ESMO Clinical Practice Guidelines for diagnosis, treatment and follow-up. Ann Oncol 2014; 25 (Suppl 3):iii93-101.

20 Weller M, van den Bent M, Hopkins K, Tonn JC, Stupp R, Falini A, et al.; European Association for Neuro-Oncology (EANO) Task Force on Malignant Glioma. EANO guideline for the diagnosis and treatment of anaplastic gliomas and glioblastoma. Lancet Oncol 2014; 15:e395-e403. 


\section{AUTHOR QUERY FORM}

\section{LIPPINCOTT \\ WILLIAMS AND WILKINS}

JOURNAL NAME: NMC

ARTICLE NO: NMC-11-3713

QUERIES AND / OR REMARKS

\begin{tabular}{|l|l|l|}
\hline QUERY NO. & Details Required & Author's Response \\
\hline Q1 & $\begin{array}{l}\text { Please check and confirm the title of the } \\
\text { article. }\end{array}$ & \\
\hline Q3 & $\begin{array}{l}\text { Please provide affiliation details for } \\
\text { Yazeed Aldalilah and Jamshed Bomanji. }\end{array}$ & \\
\hline Q4 & $\begin{array}{l}\text { For indexing purposes, please confirm } \\
\text { that author names have been correctly } \\
\text { identified as given names (blue), } \\
\text { surnames (red), and suffixes (black). } \\
\text { Color in the byline will not appear on } \\
\text { the final published version. }\end{array}$ & \\
\hline Q5 & $\begin{array}{l}\text { Please provide the missing department, } \\
\text { city, and state name for affiliation a. }\end{array}$ & \\
\hline Q6 & $\begin{array}{l}\text { Please provide the missing telephone } \\
\text { number for the corresponding author. }\end{array}$ & \\
\hline Q7 & $\begin{array}{l}\text { Please provide the missing department, } \\
\text { city, and state name for affiliation a. }\end{array}$ & \\
\hline Q8 & $\begin{array}{l}\text { Please provide expansion for NHS-E } \\
\text { and MHRA. }\end{array}$ & \\
\hline & $\begin{array}{l}\text { Please confirm the conflicts of interest } \\
\text { statement. }\end{array}$ & \\
\hline
\end{tabular}

